\title{
COMPLEX TITANIUM-CONTAINING REAGENTS IN THE PROCESSES OF WASTE WATER TREATMENT IN THE METALLURGICAL INDUSTRY
}

\author{
Evgenii KUZIN, Natalya KRUCHININA, Tatyana NOSOVA, \\ Mendeleev University of Chemical Technology, Moscow, Russia, e.n.kuzin@mail.ru
}

https://doi.org/10.37904/metal.2021.4215

\begin{abstract}
The growth of industrial production dictates the need to search for new technologies for environmental protection. Complex titanium-containing reagents have proven themselves well in wastewater treatment processes of various origins, however, the processes of obtaining such reagents for the needs of water purification are practically not described in the literature. As part of the study, work was carried out to obtain samples of complex titanium-containing reagents in the process of sulphuric acid processing of large-tonnage titanium-containing mineral waste. Evaluation of the efficiency of the obtained reagents in the processes of wastewater treatment of galvanic, machine-building and metallurgical production is carried out. A conceptual scheme for processing large-tonnage titanium-containing waste to obtain reagents for wastewater treatment is proposed.
\end{abstract}

Keywords: Titanium-containing regents, waste, recycle, water treatment

\section{INTRODUCTION}

The growth of industrial production leads to an inevitable increase in the consumption of fresh, clean water, and, therefore, to an increase in the volume of wastewater formation. Considering the constantly tightening legislation, as well as the problem of lack of clean water in certain regions, it is necessary to search for new highly efficient and economically viable methods for treating various wastewaters.

Most industrial enterprises have at their disposal systems for local wastewater treatment, from where pretreated wastewater is discharged into a centralized sewerage network for further additional treatment at urban deep biological treatment facilities.

Metallurgical cleaning enterprises are a specific direction of the industry, including directly metallurgical, machine-building, galvanic and other types of industries. All these industries are characterized by the formation of significant amounts of waste, but most of them can be used repeatedly in the recycling water supply system [1]. The main sources of the formation of contaminated wastewater are gas cleaning units for off-gases from steel-making furnaces and coking areas [2], areas for hydro-treating the surface of parts [3] and rinsing waters of electroplating processes [4].

For the purification of such effluents, special reagents are used - coagulants, which make it possible to remove insoluble mineral impurities and colloidal particles from water with high efficiency. Usually, aluminum or iron salts are used for such purposes. Despite the relatively high efficiency and low cost, these reagents have several disadvantages, as aluminum compounds are effective in a limited $\mathrm{pH}$ range, and iron compounds form a fine suspension in water with high corrosive and abrasive properties [5].

Recently, more and more information about the high prospects of using titanium salts in wastewater treatment processes of various origins has been encountered $[6,7]$. Unfortunately, these reagents are used in the form of pure compounds, which negatively affects the cost of the process. A way out of the situation can be the use of complex titanium-containing reagents obtained by adding titanium salts to traditional reagents $[8,9]$. 
The main goal of this work is to develop a technology to produce complex titanium-containing reagents based on large-tonnage mineral waste. An additional task is to evaluate the effectiveness of the obtained reagent in the processes of wastewater treatment in the metallurgical industry.

\section{MATERIALS AND METODS}

The chemical composition of solid samples was determined by X-ray fluorescence analysis on a JEOL 1610LV scanning electron microscope with an SSD X-Max Inca Energy dispersive spectrometer for electron probe microanalysis (JEOL, Japan; Oxford Instruments, Great Britain).

A sample of a complex titanium-containing coagulant was obtained by treating a mixture of mineral wastes from the apatite mining process (sphene and nepheline) with sulphuric acid solutions of various concentrations under constant heating. The resulting cake was dissolved in water, the unreacted residue was decanted and analyzed for the content of the main components.

The content of soluble form of metals in solutions was measured on a Spectroskai atomic emission spectrometer (Korolev, Russia) [10]. The content of suspended solids (purification efficiency) was measured by the gravimetric method and using a portable turbidity meter HANNA 98703 (HACH USA).

The study of the coagulating ability of the resulting solution was carried out on a laboratory flocculator VELP 4 (Velp Scientifica, Italy). The time of rapid mixing of the coagulant with water was 2 minutes, flocculation was 8 minutes, sedimentation was 30 minutes.

The sedimentation rate was determined visually in graduated cylinders by noting the settling time of large aggregates, and the filtration rate by passing water through a filter with a filtration rating of 15 microns for 60 seconds.

\section{RESULT AND DISCUSSION}

A large-tonnage mineral waste from the apatite mining process (raw material for the production of extraction phosphoric acid) was chosen as a feedstock for obtaining a complex titanium-containing coagulant. Waste by its nature is a mixture of nepheline $\left((\mathrm{Na}, \mathrm{K})_{2} \mathrm{O} \cdot \mathrm{Al}_{2} \mathrm{O}_{3} \cdot 2 \mathrm{SiO}_{2}\right)$ and sphene $\left.(\mathrm{CaTiSiO})_{5}\right)$ concentrates. Table 1 demonstrates data on the chemical composition of solid samples of mineral waste obtained by $\mathrm{X}$-ray fluorescence analysis.

Table 1 Elemental composition of samples (wt\%)

\begin{tabular}{|c|c|c|c|c|c|c|}
\hline $\mathrm{Fe}_{2} \mathrm{O}_{3}$ & $\mathrm{TiO}_{2}$ & $\mathrm{SiO}_{2}$ & $(\mathrm{~K}, \mathrm{Na})_{2} \mathbf{O}$ & $\mathbf{A l}_{2} \mathbf{O}_{3}$ & $\mathbf{C a O}$ & $\mathbf{M g}, \mathbf{P}$, et all. \\
\hline 3.95 & 5.77 & 41.83 & 11.27 & 24.32 & 8.09 & 4.77 \\
\hline
\end{tabular}

From the data (Table 1) in the composition of the waste, in addition to aluminum compounds, there are compounds of titanium, silicon, iron and calcium. Based on the elemental composition, it can be assumed that during the processing of mineral waste from the apatite mining process with sulphuric acid, mainly iron, titanium and aluminum compounds will go into solution, and inert silicon dioxide and poorly soluble calcium sulphate formed during processing will remain in the solid phase and will be isolated from solution during decantation. The resulting sediment containing silicon and calcium compounds after washing and neutralization can be used as an additive to building materials.

The process of sulphuric acid treatment was carried out at a ratio of waste: sulphuric acid 1:2, without additional heating, changing the concentration of sulphuric acid. The process time was 120 minutes, the temperature of the reaction mixture was $90-95{ }^{\circ} \mathrm{C}$. Table 2 shows the experimental data about the parameter of reaction and recovery rate of base components. 
Table 2 Experimental conditions

\begin{tabular}{|c|c|c|c|c|c|}
\hline & & \multirow{2}{*}{$\begin{array}{c}\text { Ratio } \\
\text { No }\end{array}$} & $\begin{array}{c}\text { Concentration of } \\
\text { Wuste:Sulphuric acid }\end{array}$ & \multicolumn{3}{|c|}{ Recovery rate of components (\%) } \\
\cline { 4 - 6 } & sulphuric acid (wt\%) & Fe & Ti & Al \\
\hline 1 & $1: 2$ & 10 & 83.2 & 58.1 & 80.9 \\
\hline 2 & $1: 2$ & 15 & 87.3 & 62.6 & 85.2 \\
\hline 3 & $1: 2$ & 20 & 95.1 & 74.7 & 91.6 \\
\hline 4 & $1: 2$ & 25 & 98.7 & 83.6 & 95.8 \\
\hline 5 & $1: 2$ & 30 & 98.8 & 92.2 & 95.9 \\
\hline
\end{tabular}

From the data (Table 2) at an acid concentration of $25 \mathrm{wt} \%$ (sample No. 4), almost complete extraction of aluminum and iron compounds is achieved. In addition, a small amount of calcium compounds (5-7 wt\%) and silicon passes into the solution. A further increase in the acid concentration is impractical due to a relatively small increase in the degree of titanium extraction, a significant increase in the consumption of reagents and energy consumption, as well as the solidification of the reaction mixture due to the polymerization of silicic acids [11-12].

Data on the chemical composition of the purified (passed the stage of separation of the unreacted precipitate and recrystallization) obtained reagents are presented in Table 3.

Table 3 Chemical composition of a sample of a complex titanium-containing coagulant (wt\%)

\begin{tabular}{|c|c|c|c|}
\hline $\mathrm{FeSO}_{4} \cdot \mathbf{7 \mathrm { H } _ { 2 } \mathrm { O }}$ & $\mathbf{A l}_{2}\left(\mathbf{S O}_{4}\right)_{3} \cdot \mathbf{1 8 \mathrm { H } _ { 2 } \mathrm { O }}$ & $\mathrm{TiOSO}_{4} \cdot \mathrm{H}_{2} \mathrm{O}$ & $\mathrm{CaSO}_{4} \cdot \mathbf{2} \mathbf{H}_{2} \mathbf{O}$ \\
\hline 9.65 & 82.70 & 6.88 & 0.78 \\
\hline
\end{tabular}

From the data (Table 3 ) in terms of its chemical composition, the complex titanium-containing coagulant is a mixture of aluminum and iron sulphates, while the dose of the modifying additive of titanium compounds does not exceed $7 \mathrm{wt} \%$, which suggests the manifestation of a synergistic effect and the possibility of increasing the purification efficiency [8-9].

The obtained samples of a complex-titanium-containing coagulant were compared with samples of pure aluminum sulfate, as well as a mixture of aluminum and iron sulphate. The equivalent dose of the reagents was $100 \mathrm{mg} / \mathrm{L}$ in terms of pure (anhydrous) salts. The data on treatment efficiency (indicator of suspended solids content) for various wastewaters of metallurgical production are presented in the graph (Figure 1).

The initial content of suspended solids for water samples was:

1) Waste water from galvanic production $-256.9 \mathrm{mg} / \mathrm{L}$. $\mathrm{pH}-5.2$;

2) The combined industrial and household flow of a machine-building enterprise - $134.6 \mathrm{mg} / \mathrm{L} . \mathrm{pH}-6.1$;

3) Waste water from the hydro-treating unit for metallurgical production parts - $807.6 \mathrm{mg} / \mathrm{L}$. pH - 7.2;

4) Waste water from the gas cleaning plant of an electro-induction steelmaking furnace of metallurgical production - $692.5 \mathrm{mg} / \mathrm{L}$. $\mathrm{pH}$ - 6.6.

From the data of the diagram (Figure 1) we can see that binary coagulants (a mixture of aluminum and iron sulphates) are superior in efficiency to a pure reagent based on aluminum compounds for all studied wastewater samples. The reduced efficiency of aluminum sulphate can be explained by the acidic nature of the reagent and the effluent outflow beyond the optimal $\mathrm{pH}$ range 6.0-8.5 [5]. 


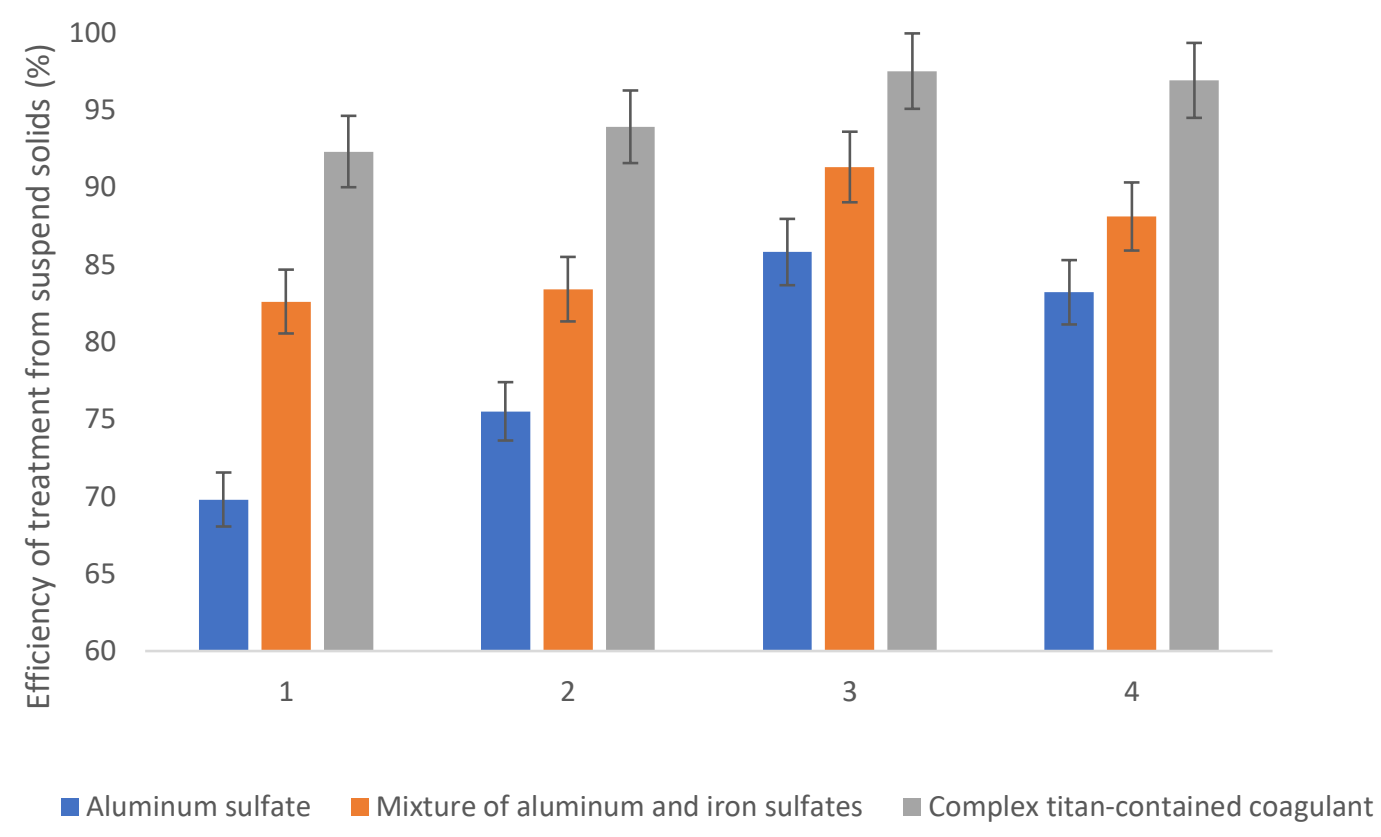

Figure 1 The efficiency of wastewater treatment of a metallurgical enterprise from suspended solids

Moreover, the addition of titanium further intensifies the purification processes, even in comparison with binary coagulants based on a mixture of aluminum and iron sulphates. This phenomenon can be described both by specific hydrolysis phenomena of titanium compounds and by nucleation processes due to neutralization of positively charged hydroxocomplexes of aluminum and iron by negatively charged hydroxocomplexes of titanium [5,11-13].

During monitoring the cleaning, it was noted that the coagulation slimes obtained using titanium-containing reagents quickly settle to the bottom, give off moisture more easily and have a denser structure. Data on sedimentation rate and filtration rate of coagulation sludge are presented in the diagrams (Figure 2 and 3 ).

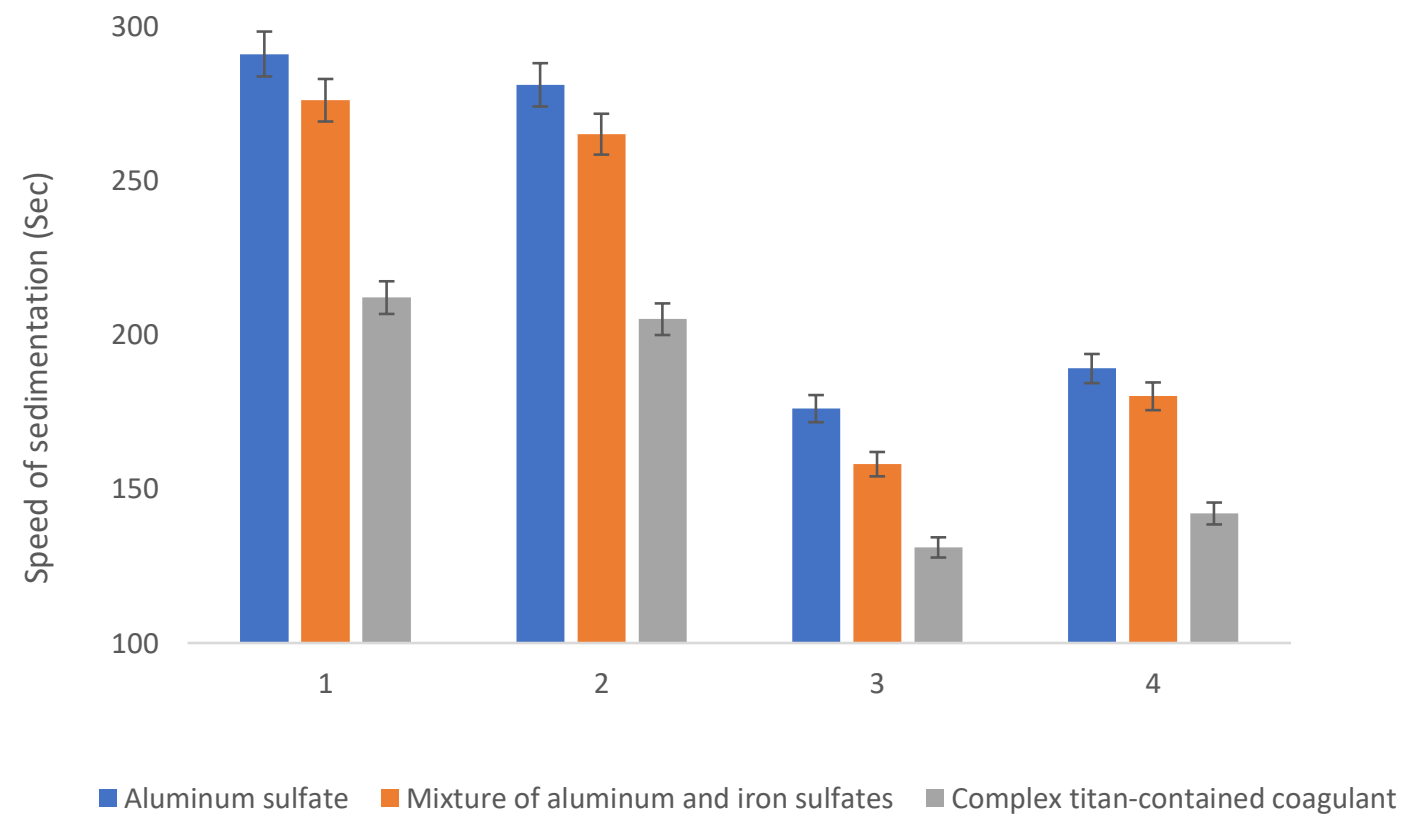

Figure 2 Sedimentation rate of coagulation sludge 


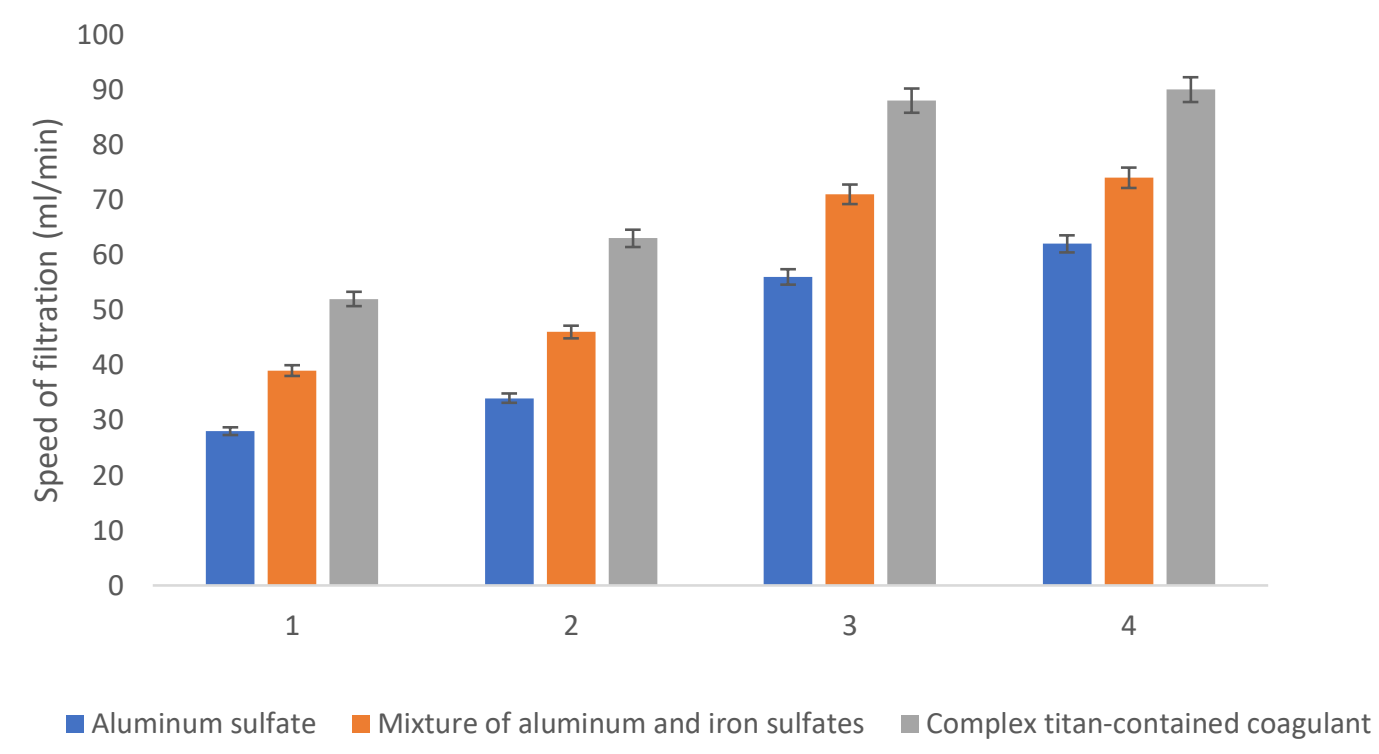

Figure 3 Filtration rate of coagulation sludge

From these graphs (Figure 2 and $\mathbf{3}$ ) the rate of sedimentation and filtration of coagulation sludge increases in the following order:

\section{Complex titan-contained coagulant $>$ mixture of iron and aluminum sulfate $>$ aluminum sulfate}

The use of complex titanium-containing coagulants makes it possible to intensify the processes of sedimentation of coagulation sludge by $20-25 \%$, and filtration by $15-20 \%$.

\section{CONCLUSION}

As part of the work done, the elemental composition of large-tonnage mineral waste from the apatite mining process has been studied. It has been established that in the composition of mineral waste there are significant amounts of compounds of aluminum (up to $25-30 \mathrm{wt} \%$ ), iron and titanium (up to $5 \mathrm{wt} \%$ ), presumably in the form of complex oxides.

The assessment of the possibility of sulphuric acid leaching of the main components from the mineral waste of the apatite mining process has been carried out. It was found that sulphuric acid with a concentration of 25 wt $\%$ is optimal in terms of flow rate / recovery. A further increase in the acid concentration leads to an overconsumption of reagents, an increase in the cost of the process and the hardening of the reaction mixture due to the ongoing polycondensation reactions of active silicic acid. The chemical composition of a solid sample of a complex titanium-containing coagulant was determined: $\mathrm{FeSO}_{4} \cdot 7 \mathrm{H}_{2} \mathrm{O}-9.65 \% ; \mathrm{Al}_{2}\left(\mathrm{SO}_{4}\right)_{3} \cdot 18 \mathrm{H}_{2} \mathrm{O}$ - 82.70\%; $\mathrm{TiOSO}_{4} \cdot \mathrm{H}_{2} \mathrm{O}-6.88 \% ; \mathrm{CaSO}_{4} \cdot 2 \mathrm{H}_{2} \mathrm{O}-0.78 \%$.

The samples obtained showed a high efficiency of purification of various waste waters of metallurgical production in comparison with pure reagents. On average, complex titanium-containing coagulants were 10 $15 \%$ more effective than mixed coagulants based on aluminum and iron sulphates and about $25 \%$ more effective than pure aluminum sulphate. In addition, it was noted that complex reagents (both mixture and titanium-containing) were less sensitive to changes in the $\mathrm{pH}$ of the treated water.

The influence of titanium compounds on the cleaning efficiency has been proven. It was found that the addition of titanium compounds makes it possible to significantly intensify the processes of sedimentation (acceleration by $20-25 \%$ ) and filtration (acceleration by $15-20 \%$ ) of coagulation sludge, which will significantly increase the productivity of local treatment facilities, reduce their size, and most importantly, significantly improve the efficiency of their work. 
The coagulation sludge formed during the reagent treatment can be effectively removed using standard technological equipment (for example, an electro-flotator [14,15]).

\section{ACKNOWLEDGEMENTS}

This work was supported by the Mendeleev's University of Chemical Technology through the Internal Bridging Grants for Young Science Educators Contest, proposal no. Z-2020-013.

\section{REFERENCES}

[1] AVERINA, J.M., KALIAKINA, G.E., ZHUKOV, D.Y., KURBATOV, A.Y., SHUMOVA, V.S. Development and design of a closed water use cycle. In: 19th International Multidisciplinary Scientific Geoconference (SGEM 2019). Bulgary, 2019, vol. 19 of 3.1., pp. 145-152.

[2] KUZIN, E.N., KRUTCHININA, N. E. Purification of circulating and waste water in metallurgical industry using complex coagulants. CIS Iron and Steel Review. 2019, vol. 18, pp. 72-75.

[3] KUZIN, E.N., KRUCHININA, N.E. Titanium-containing coagulants for foundry wastewater treatment CIS Iron and Steel Review. 2020, vol. 20, pp. 66-69.

[4] AVERINA, YU.M., KALYAKINA, G.Ye., MEN'SHIKOV, V.V., KAPUSTIN, Yu. I., BOLDYREV, V.S. Design of processes for neutralization of chromium and cyanogenous waste water using the example of galvanic production. Herald of the Bauman Moscow State Technical University. Series Natural Sciences. 2019, no. 3, pp. 70-80.

[5] DRAGINSKY, V.L., ALEKSEEVA, L.P., GETMANTSEV, S.V. Coagulation in the technology of purification of the natural water. Moscow: Sci. Ed., 2005. In Russian.

[6] GAN, Y., LI, J., ZHANG, L., WU, B., HUANG, W., LI, H., ZHANG, S. Potential of titanium coagulants for water and wastewater treatment: Current status and future perspectives. Chemical Engineering Journal. 2020, no. 126837.

[7] THOMAS, M., BĄK, J., KRÓLIKOWSKA, J. Efficiency of titanium salts as alternative coagulants in water and wastewater treatment: Short review. Desalination and Water Treatment. 2020, vol. 208, pp. 261-272.

[8] SHON, H. K., VIGNESWARAN, S., KANDASAMY, J., ZAREIE, M. H., KIM, J. B., CHO, D. L., KIM, J.-H. Preparation and characterization of titanium dioxide $\left(\mathrm{TiO}_{2}\right)$ from sludge produced by $\mathrm{TiCl}_{4}$ flocculation with $\mathrm{FeCl}_{3}$, $\mathrm{Al}_{2}\left(\mathrm{SO}_{4}\right)_{3}$ and $\mathrm{Ca}(\mathrm{OH})_{2}$ coagulant aids in wastewater. Separation Science and Technology. 2009, vol. 44, no. 7 , pp. 1525-1543.

[9] IZMAILOVA, N.L., LORENTSON, A.V., CHERNOBEREZHSKII, Y.N. Composite coagulant based on titanyl sulfate and aluminum sulfate. Russ. J. Appl. Chem. 2015, vol. 88, pp. 458-462.

[10] KUCHUMOV, V.A., SHUMKIN, S.S. Analysis of the chemical composition of the initial alloy in the production of permanent magnets from alloys of the Sm-Co system. Scientific-technical department of St. Petersburg State Polytechnic University. 2017, vol. 23, no. 1, pp. 219-225.

[11] SHABANOVA, N.A., POPOV, V.V., SARKISOV, P.D. Chemistry and technology of nanodispersed oxides. Moscow: Akademkniga, 2007. In Russian.

[12] WANG, T-H., NAVARRETE-LÓPEZ. A. M., LI, S., DIXON, D.A., GOLE, J.L. Hydrolysis of $\mathrm{TiCl}_{4}$ : initial steps in the production of TiO. J. Phys. Chem. A. 2010, vol. 114, no. 28, pp. 7561-7570.

[13] PARK, H.K., KIM, D.K., KIM, C.H. Effect of solvent on titania particle formation and morphology in thermal hydrolysis of TiCl4. Journal of the American Ceramic Society. 1997, vol. 80, no. 3, pp. 743-749.

[14] KOLESNIKOV, A.V., SAVEL'EV, D.S., KOLESNIKOV, V.A., DAVYDKOVA, T.V. Electroflotation extraction of highly disperse titanium dioxide $\mathrm{TiO}_{2}$ from water solutions of electrolytes. Glass and Ceramics. 2018, vol. 75, no. 5-6, pp. 237-241.

[15] MESHALKIN, V.P., KOLESNIKOV, A.V., SAVELIEV, D.S. Analysis of physicochemical efficiency of electroflotation process for removing titanium chloride hydrolysis products from the anthropogenic effluents. Deport of the Academy of Sciences. 2019, vol. 486, no. 6, pp. 680-684. 